\title{
ENHANCEMENT OF THE CONVECTIVE COOLING OF TWO HEATERS IN A RECTANGULAR DUCT BY IMPINGING JETS
}

\author{
I. Marchi Neto ${ }^{\mathrm{a}}$, \\ and C. A. C. Altemani ${ }^{\text {b }}$ \\ ${ }^{a}$ Universidade Tecnológica Federal do Paraná \\ Coordenação de Engenharia Mecânica \\ Bairro Santa Cruz \\ CEP. 85015-430, Guarapuava, Paraná, Brasil \\ ismaelneto@utfpr.edu.br

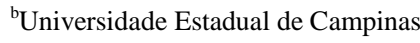 \\ Faculdade de Engenharia Mecânica \\ Departamento de Energia \\ Cidade Universitária \\ CEP. 13083-860, Campinas, SP, Brasil \\ Received: October 25, 2013 \\ Revised: November 21, 2013 \\ Accepted: December 20, 2013
}

\section{ABSTRACT}

A numerical investigation was performed to compare two alternative configurations for the convective air cooling of two heaters flush mounted on the lower horizontal wall of a rectangular duct. One configuration consisted of duct flow with uniform airflow velocity and temperature at the duct inlet and the heaters were located in the flow entrance region. In the other, the cooling was obtained by impinging air jets exiting with uniform velocity and temperature from two square holes on the upper duct wall just above the heaters. The simulations were performed under steady state conditions considering the three dimensional flow region of each configuration, where the conservation equations were solved. The results were presented in the form of the adiabatic Nusselt number and a dimensionless pressure drop for both configurations, in the range of the duct Reynolds number from 500 to 9,000 .

Keywords: impinging jets, convective cooling, flush heaters, forced convection, pumping power.

\section{NOMENCLATURE}

a edge of the heaters, $m$

$\mathrm{D}_{\mathrm{h}} \quad$ duct hydraulic diameter

$\mathrm{Gr}$ Grashoff number

$\mathrm{H} \quad$ distance from the jet exit to the impinging

surface, $m$

$\mathrm{L} \quad$ length of cross section, $\mathrm{m}$

$\mathrm{P}$ pressure, $\mathrm{N} / \mathrm{m}^{2}$

Re Reynolds number

$\mathrm{T}$ temperature, ${ }^{\circ} \mathrm{C}$

$\mathrm{T}_{\mathrm{w}} \quad$ temperature of heaters, ${ }^{\circ} \mathrm{C}$

$\mathrm{V}$ velocity, $\mathrm{m} / \mathrm{s}$

$\mathrm{x}_{\mathrm{i}}, \mathrm{x}_{\mathrm{j}}$ velocity components in the coordinate directions

W jet width, $m$

\section{Greek symbols}

$\alpha \quad$ thermal diffusivity, $\mathrm{m}^{2} / \mathrm{s}$

$\varepsilon_{\mathrm{M},} \varepsilon_{\mathrm{H}}$ turbulent diffusivities

$v \quad$ fluid kinematic viscosity, $\mathrm{m}^{2} / \mathrm{s}$

$\rho$ density, $\mathrm{kg} / \mathrm{m}^{3}$

\section{Subscripts}

D parallel flow configuration

e inlet airflow

$\mathrm{J}$ impinging flow configuration

$\mathrm{x}, \mathrm{y}, \mathrm{z}$ cartesian coordinates

\section{INTRODUCTION}

Electronic equipments usually contain circuit boards with several electronic components which operate reliably only within a limited range of temperatures, specified by their manufacturers. Due to ohmic dissipation during their operation, the components must be cooled and air is usually the preferred fluid, due to its availability, handling facilities and high dielectric strength. Its thermal properties are however typical of gases, associated to relatively low convective coefficients. Thus, under severe operating conditions, the components temperatures may exceed their reliable limit unless some heat transfer enhancement technique is employed for their cooling.

There are several alternatives such as finned heat sinks mounted on top of these components, conductive circuit boards and jet flow impingement. Single jets or jet arrays are usually used for enhanced convective heat and mass transfer in several applications of industrial interest (Zuckerman and Lior, 2006). In electronics cooling applications, the available space is often restricted, so that the aspect ratio $(\mathrm{H} / \mathrm{W})$ of the distance $(\mathrm{H})$ from the jet exit to the impinging surface and the jet width (W) or diameter is usually close to one. Due to this, turbulence augmentation devices have been proposed at the jet exit, as in Danek and Moffat (1995), showing an increase of the average heat transfer coefficient over the open jet case. Guarino and Manno (2002) 
performed a numerical investigation of laminar jet cooling in portable computer applications. The first part of their study considered a simplified CPU compartment, while a second part was associated to a full sized laptop computer. Their results indicated the importance of the jet Reynolds number on the cooling characterization rather than the jet size. Effects of natural convection were noticed only when the Grashoff to Reynolds number ratio, $\mathrm{Gr} / \mathrm{Re}^{2}$, was larger than 5. Kunugi et al. (1993) presented experimental data and the results of numerical simulations of the convective heat transfer coefficient due to a confined slot air jet impinging on a uniform heat flux surface. Their experimental results were obtained for the geometric ratio $(\mathrm{H} / \mathrm{W})$ in the range from 0.25 to 1.5 and the Reynolds number based on the jet width $\operatorname{Re}=8000$. The simulations with an anisotropic k- $\varepsilon$ turbulence model agreed reasonably with the experimental data. Ichimiya and Hosaka (1992) presented experimental data for the impingement cooling of a uniform heat flux surface by three confined slot jets. The experiments were run with the Reynolds number, based on the jet width, in the range from 500 to 8000 and an aspect ratio (H/W) in the range from 0.25 to 1.5 . For $R e=500$ and only one jet, the experimental results showed a single peak of the heat transfer coefficient at the stagnation line of the impinging surface.

The purpose of the present work is to compare, by numerical simulations, two alternative configurations for the cooling of two flush mounted discrete heaters on the lower wall of a rectangular duct. The first configuration was the standard parallel flow with uniform velocity and temperature at the rectangular duct inlet, considering the simultaneous flow and thermal development regions. The second investigated configuration was obtained from the previous configuration by closing the rectangular duct inlet and forcing the flow by two jets located on the upper wall of the duct, just above the discrete heaters. The flow and temperature profiles were also uniform at the jet exit.

\section{MODEL DESCRIPTION}

The present investigation was performed to evaluate the enhancement of the convective cooling of two heaters in a rectangular duct by impinging jets. A comparison was made with the cooling and flow characteristics of the two heaters in a rectangular duct considering the two distinct configurations indicated in Fig. 1 and Fig. 2. In each configuration two identical heaters were flush mounted on the lower wall of a rectangular duct. The heaters had a square section with an edge $\mathrm{a}=0.05 \mathrm{~m}$ and they were located symmetrically in the duct, as indicated in Fig. 1 and Fig. 2, with their upstream edge at $0.025 \mathrm{~m}$ from the duct entrance. The two heaters were equally separated from the mid-plane at $\mathrm{x}=0.08 \mathrm{~m}$ by a distance equal to $0.005 \mathrm{~m}$. The configuration in Fig. 1 shows the heaters cooling by a parallel forced airflow in the rectangular duct, with uniform velocity profile at the duct entrance (plane $\mathrm{z}=0$ ), with a cross section $\mathrm{L}_{\mathrm{x}}=0.16 \mathrm{~m}$ and $\mathrm{H}=0.02 \mathrm{~m}$. In the configuration shown in Fig. 2, the heaters size and position is the same as in Fig. 1, but they are cooled by the impinging flows from two jets located at the upper duct wall, $\mathrm{y}=\mathrm{H}$, centered just above the heaters. Both jets had a square section with an edge $\mathrm{W}=0.04 \mathrm{~m}$ and a uniform velocity at the jets exit. Thus, the cross section sum of the two jets was equal to that of the rectangular duct in the previous configuration. In Fig. 2 the rectangular duct is closed by a wall at the plane $\mathrm{z}=0$, so that the jets airflow was channeled through the duct and exited downstream at the plane $\mathrm{z}=\mathrm{L}_{\mathrm{z}}$. The heaters were assumed isothermal at $\mathrm{T}_{\mathrm{w}}=22^{\circ} \mathrm{C}$ and the remaining walls of the duct were adiabatic. In both configurations, the inlet airflow velocity was uniform $\left(\mathrm{V}_{\mathrm{e}}\right)$, with a uniform temperature $\mathrm{T}_{\mathrm{e}}=18^{\circ} \mathrm{C}$. All the air properties were taken at $20^{\circ} \mathrm{C}$.

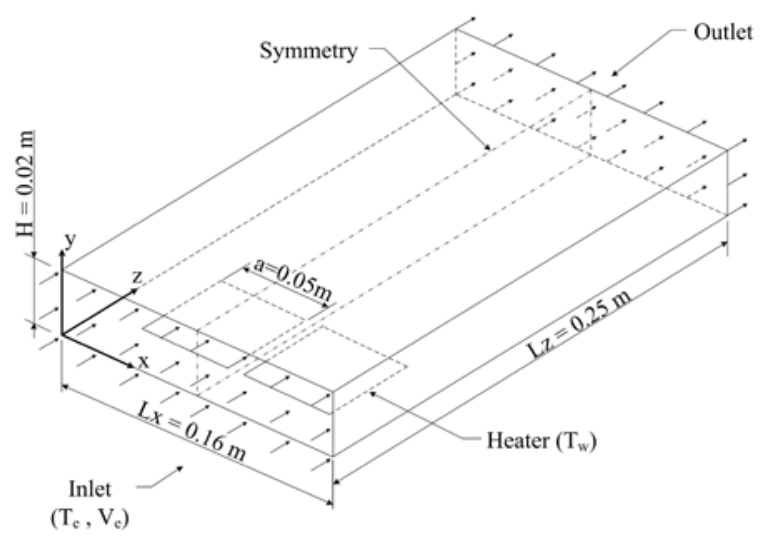

Figure 1. Parallel flow configurations for the heaters in a rectangular duct.

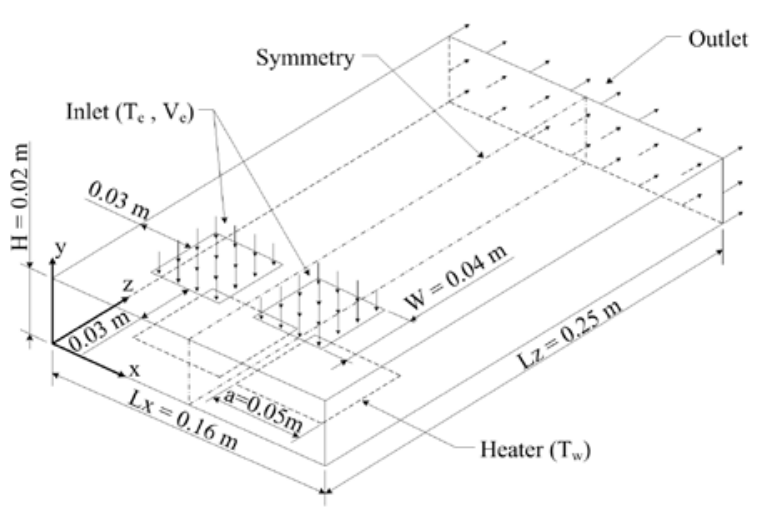

Figure 2. Impinging flow configurations for the heaters in a rectangular duct.

Both configurations presented in Fig. 1 and Fig. 2 have the same total inlet cross section $\left(\mathrm{HL}_{\mathrm{x}}=2 \mathrm{~W}^{2}\right)$ and also the same cross section $\left(\mathrm{H} \cdot \mathrm{L}_{\mathrm{x}}\right)$ at the flow outlet. Thus, for the same inlet flow velocity, both will have the same mass flow rate and 
the same Reynolds number $\operatorname{Re}_{\mathrm{D}}$ based on the rectangular duct hydraulic diameter $\mathrm{D}_{\mathrm{h}}=2 \mathrm{HL}_{\mathrm{x}} /\left(\mathrm{H}+\mathrm{L}_{\mathrm{x}}\right)$. Thus, $\mathrm{Re}_{\mathrm{D}}$ will be used as a basis for comparison of the numerical results for the two configurations. For the considered geometry, the Reynolds number $\operatorname{Re}_{\mathrm{J}}$ based on the hydraulic diameter (W) of each jet is related to $\operatorname{Re}_{\mathrm{D}}$ as $\operatorname{Re}_{\mathrm{J}}=1.125 \operatorname{Re}_{\mathrm{D}}$.

\section{NUMERICAL PROCEDURE}

The mass, momentum and energy conservation equations, considering constant air properties at $20^{\circ} \mathrm{C}$, were solved in the Cartesian three dimensional domains presented in Fig. 1 and Fig. 2. For turbulent flows, the Reynolds averaged conservation mass, momentum and energy equations were respectively expressed by

$$
\frac{\partial V_{i}}{\partial x_{i}}=0
$$

$$
\begin{gathered}
\frac{\partial V_{i} V_{j}}{\partial x_{j}} \\
=-\frac{1}{\rho} \frac{\partial P}{\partial x_{i}}+\frac{\partial}{\partial x_{j}}\left[\left(v+\varepsilon_{M}\right)\left(\frac{\partial V_{i}}{\partial x_{j}}+\frac{\partial V_{j}}{\partial x_{i}}\right)\right] \\
\frac{\partial\left(V_{j} T\right)}{\partial x_{j}}=\frac{\partial}{\partial x_{j}}\left[\left(\alpha+\varepsilon_{H}\right) \frac{\partial T}{\partial x_{j}}\right]
\end{gathered}
$$

The Cartesian coordinates are represented by $\mathrm{x}_{\mathrm{i}}$ and $\mathrm{x}_{\mathrm{j}}$, the velocity components in the coordinate directions are indicate by $\mathrm{V}_{\mathrm{i}}$ and $\mathrm{V}_{\mathrm{j}}$ and the flow pressure and temperature respectively by $\mathrm{P}$ and $\mathrm{T}$. The fluid properties are the density $\rho$, the kinematic viscosity $v$, and the thermal diffusivity $\alpha$. The turbulent diffusivities $\varepsilon_{\mathrm{M}}$ and $\varepsilon_{\mathrm{H}}$ were obtained from the LVEL turbulence model, described by Spalding et al. (1996). The turbulent Prandtl number, relating these two diffusivities, was equal to one. The boundary conditions were described previously, comprising uniform inlet airflow velocity and temperature for both configurations and isothermal heaters, while all the remaining duct walls were adiabatic. As the duct Reynolds number $\operatorname{Re}_{\mathrm{D}}$ and the wall shear stresses due to the flow decrease, the turbulent diffusivities of the adopted model almost vanish, so that the effective diffusivities of the momentum and energy equations become respectively just $v$ and $\alpha$, associated to laminar flow.

The numerical solution was obtained with the software PHOENICS (CHAM), under steady state conditions, employing the LVEL turbulence model, selected from the PHOENICS library. A non-uniform computational grid was adopted, comprising 46x40x140 control volumes respectively in the $\mathrm{x}, \mathrm{y}$ and $\mathrm{z}$ directions indicated in Fig. 1 and Fig. 2. Several numerical tests were performed with distinct grids in the solution domain in order to obtain results almost invariant with the grid. A procedure described by Celik (http://journaltool.asme.org/Templates/JFE NumAccuJFEN.pdf - accessed on: 3/9/2012), based on the Richardson extrapolation, was used to select a grid with discretization errors around 1\%. All the numerical computations were performed in a microcomputer with an Intel ${ }^{\circledR}$ Core $^{\mathrm{TM}} 2$ Quad Q6600 with $2.4 \mathrm{GHz}$ and 4GB RAM.

In order to minimize the computational effort (memory and processing time), the solution domain comprised only one half of the duct, using the indicated symmetry plane represented by $\mathrm{L}_{\mathrm{x}}=0.08 \mathrm{~m}$. With this symmetry, the solution domain had dimensions $\mathrm{L}_{\mathrm{x}}=0.08 \mathrm{~m}$, $\mathrm{L}_{\mathrm{y}}=\mathrm{H}=0.02 \mathrm{~m}$ and $\mathrm{L}_{\mathrm{z}}=0.25 \mathrm{~m}$, as indicated in Fig. 1 and Fig. 2.

\section{NUMERICAL VALIDATION}

Numerical validation tests were performed considering similar flow and heat transfer problems obtained from the literature, in order to compare the reported results with those from the present numerical procedure.

\section{Convection in the Thermal Entrance Region of Developed Channel Flow}

This test was performed in the two dimensional channel indicated in Fig. 3, with channel height and length equal to those of the present investigation. The channel had isothermal walls at $40^{\circ} \mathrm{C}$ and an air inflow at $20^{\circ} \mathrm{C}$ was fully developed from the channel entrance with an average velocity $V_{e}=0.386 \mathrm{~m} / \mathrm{s}$. The Reynolds number based on the channel hydraulic diameter $(2 \mathrm{H})$ was $\operatorname{Re}_{\mathrm{D}}=1000$, corresponding to a flow in the laminar regime.

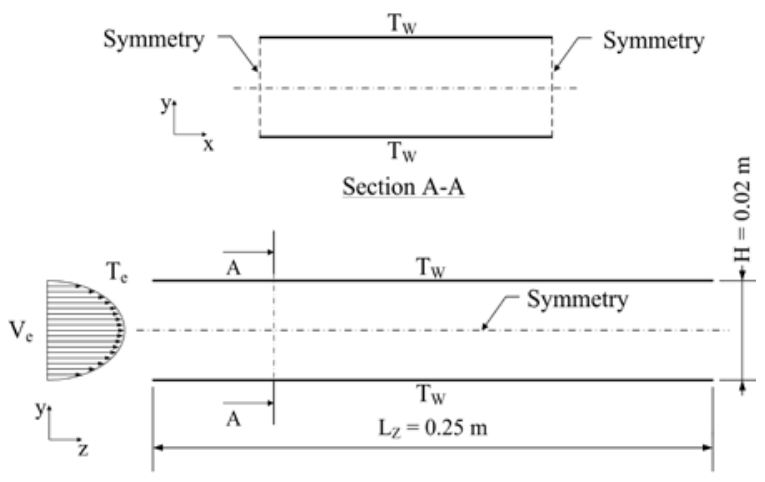

Figure 3. Dimensions and boundary conditions in channel flow.

Due to symmetry at the channel mid-plane, the computational domain comprised only half-channel, with a uniform numerical grid containing 30x250 
control volumes respectively in the $\mathrm{y}$ and $\mathrm{z}$ directions indicated in Fig. 3.

The present numerical results for the local Nusselt number based on the channel hydraulic diameter and the local mean flow temperature were compared with the analytical result presented by Kays e Crawford (1993), as shown in Fig. 4. The numerical and the analytical results agreed within $0.42 \%$.

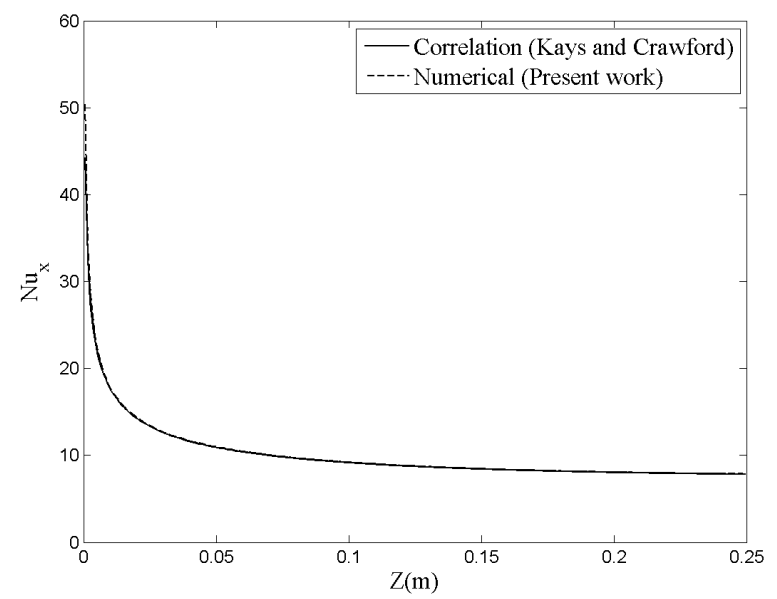

Figure 4. Local $\mathrm{Nu}_{\mathrm{x}}$ in channel flow.

\section{Convection due to confined impinging two- dimensional jets}

In this test, numerical results were obtained with the software PHOENICS and compared with the experimental data of Ichimiya and Hosaka (1992) and the numerical results of Wheeler and Neti (1999) and Guarino and Manno (2002). The configuration was that of a confined two-dimensional jet impinging on a flat plate with uniform heat flux, as indicated in Fig. 5.

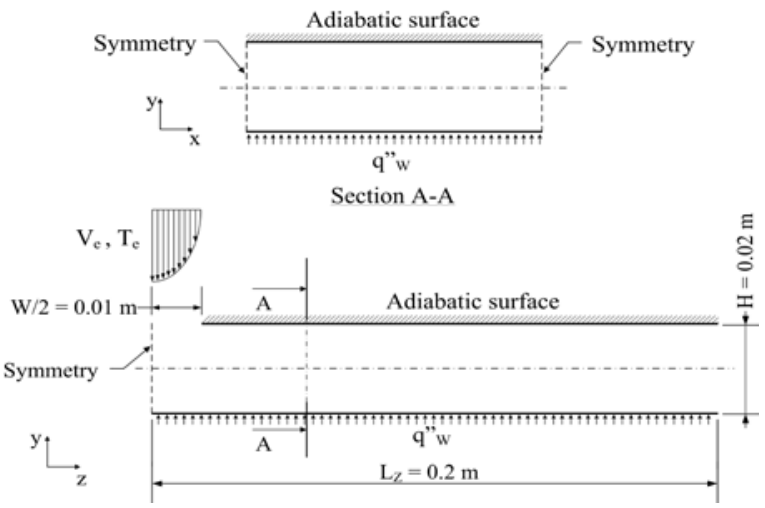

Figure 5. Duct configuration in two-dimensional confined jet.

The simulations were performed for a duct length $L_{z}=0.20 \mathrm{~m}$ from the stagnation line $(\mathrm{z}=0)$ of the jet, with a height $\mathrm{H}=0.02 \mathrm{~m}$ and a jet width $\mathrm{W}=0.02 \mathrm{~m}$. At the jet exit the air flow temperature was equal to $20^{\circ} \mathrm{C}$ and the velocity profile was fully developed with average velocity $\mathrm{V}_{\mathrm{e}}=0.386 \mathrm{~m} / \mathrm{s}$ directed towards the plate with uniform heat flux $\mathrm{q}{ }_{\mathrm{w}}=500 \mathrm{~W} / \mathrm{m}^{2}$. The Reynolds number, based on the jet width $\mathrm{W}$ and the average inlet airflow velocity was $\mathrm{Re}_{\mathrm{J}}=500$. As pointed out by Sparrow and Wong, 1975, even initially laminar slot jets may transition to turbulent flows. For this reason, the simulations were also performed employing the LVEL turbulence model for these comparative tests.

The numerical grid comprised 60 control volumes non-uniformly distributed in the direction normal to the plates and two distinct grids in the direction $\mathrm{z}$ parallel to the plates - one with 160 and the other with 635 control volumes. The results obtained for the two z-grids, presented in Fig. 6, were almost identical, indicating that 160 grid points in the z-direction were enough for the simulations. The present results for the local $\mathrm{Nu}$ distribution are quite similar to those of the two previous numerical simulations of the same problem.

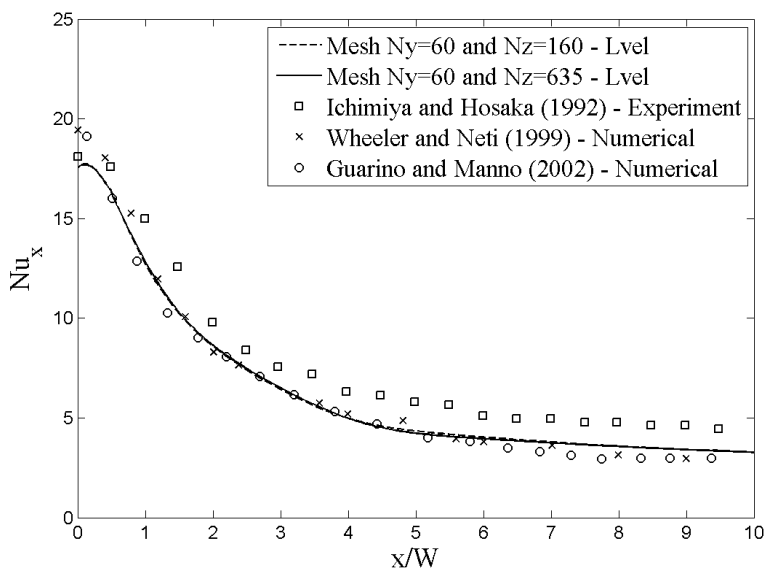

Figure 6. Local Nusselt number in two-dimensional confined jet.

\section{RESULTS AND DISCUSSION}

The heaters convective cooling obtained with the impinging flow configuration presented in Fig. 2 will be compared to that obtained with the channel cooling configuration, Fig. 1, by means of the average Nusselt number over the heater surface, defined by:

$$
\overline{N u}_{a}=\frac{q_{h}}{a^{2}\left(\bar{T}_{h}-T_{i n}\right)} \frac{a}{k}
$$

The power dissipation in each heater is $\mathrm{q}_{\mathrm{h}}$, its average temperature is $\bar{T}_{h}$, the fluid inlet temperature in the channel is $T_{\text {in }}$ and its thermal conductivity is $\mathrm{k}$. The characteristic dimension a is the square heater edge. Since the duct walls are adiabatic, Eq. (4) also indicates the adiabatic Nusselt number (Moffat, 1998). 
The numerical results for the average Nusselt number, obtained for $\mathrm{Re}_{\mathrm{D}}$ in the range from 500 to 9,000, are presented in Fig. 7 for both considered configurations. For each configuration the data were separated considering a critical $\mathrm{Re}_{\mathrm{D}}$ around 2000, typical of duct flows, and correlations were fit to both regions, as indicated in Fig. 7.

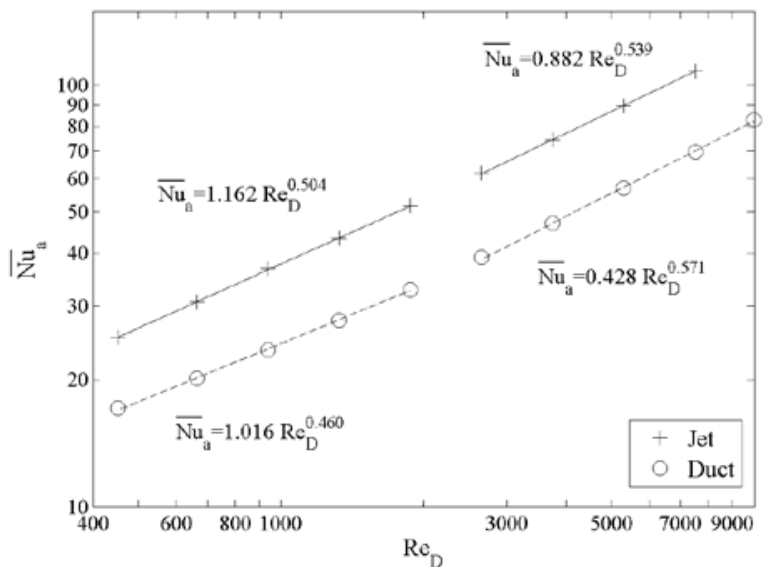

Figure 7. Average Nusselt number.

The results for both configurations are nearly parallel and they indicate that for the same $\operatorname{Re}_{D}$ the impinging flow configuration presents an average Nusselt number about $47 \%$ larger than that for the parallel flow configuration. According to Eq. (4), this means that for the same heater average temperature and duct flow rate, the allowable heater power dissipation for the impinging flow configuration is $47 \%$ larger than that for the parallel flow configuration. This convective heat transfer enhancement has however a cost in pumping power, as indicated by the results presented in Fig. 8.

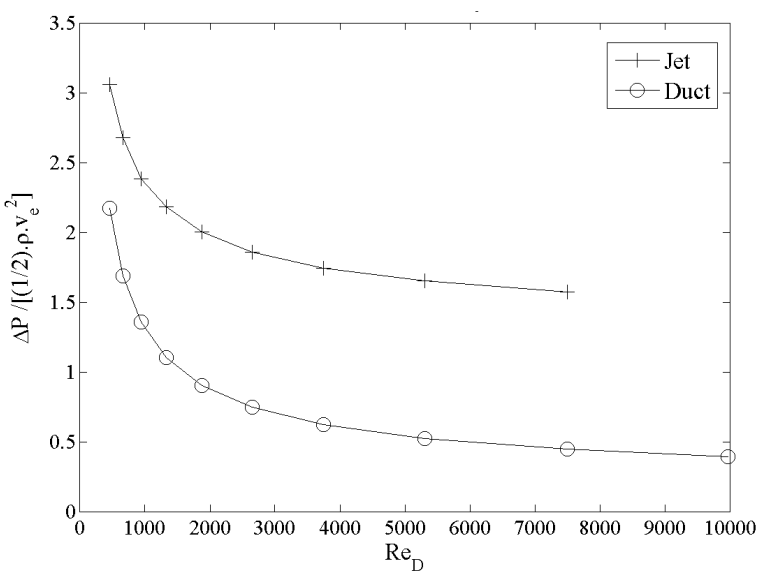

Figure 8. Dimensionless pressure drop - both configurations.

The pressure drop was obtained from the numerical results as the difference between the average flow pressure at the flow inlet and outlet cross sections of each configuration. This pressure drop was expressed in dimensionless form by its ratio with the dynamic pressure based on the inlet airflow velocity $\mathrm{V}_{\mathrm{e}}$.

Since both configurations have the same inlet cross sections, their inlet velocities and dynamic pressure will also be identical for the same $\mathrm{Re}_{\mathrm{D}}$. Thus, for a fixed $\mathrm{Re}_{\mathrm{D}}$, the required pumping power for each configuration will be proportional to the ordinate in Fig. 8. The results indicated that the pumping power required for the impinging flow configuration is always larger than that for the parallel flow configuration, with their ratio ranging from 1.5 to 3.5 as $\operatorname{Re}_{\mathrm{D}}$ increases.

\section{CONCLUSIONS}

Two alternative forced airflow configurations were compared by a numerical investigation for the convective cooling of two heaters flush mounted on the lower wall of a rectangular duct. The first configuration was related to forced duct flow and the second, to impinging flow on the heaters surfaces. The results showed that for fixed airflow inlet conditions and heater temperature, the heaters power dissipation for the impinging flow configuration is nearly $47 \%$ above that for the duct flow configuration, within the investigated $\mathrm{Re}_{\mathrm{D}}$ range. This heat transfer enhancement was obtained however at the expense of larger airflow pumping power for the impinging configuration. Considering a fixed airflow rate, the required pumping power for the impinging flow configuration varied from 1.5 to 3.5 times that for the duct flow configuration. On the other hand, for a fixed heater power dissipation, a value of $\mathrm{Nu}_{\mathrm{ad}}$ may be evaluated to keep the heater temperature below an allowable maximum value. In this case, a fixed $\mathrm{Nu}_{\mathrm{ad}}$ may be obtained for the impinging flow configuration at a much smaller $\operatorname{Re}_{D}$ than that required for the duct flow configuration. Thus, the required flow pumping power for both configurations would be much closer to each other than in the previous case. This comparison lends more credit to the impinging flow configuration.

\section{ACKNOWLEDGEMENTS}

The support of CAPES, in the form of a Doctoral Scholarship to the first author, is deeply acknowledged.

\section{REFERENCES}

Danek, C. J., and Moffat, R. J., 1995, Low Aspect Ratio Impingement Cooling of Electronic Components with Turbulence Augmentation, Advances in Electronic Packing, Vol. 10, No. 2, pp. 837-842.

Guarino, J. R., and Manno, V. P., 2002, Characterization of Laminar Jet Impingement Cooling in Portable Computer Applications, IEEE 
Transactions on Components and Packaging Technologies, Vol. 25, No. 3, pp. 337-346.

Ichimiya, K., and Hosaka, N., 1992, Experimental Study of Heat Transfer Characteristics Due to Confined Impinging Two-dimensional Jets, Experimental Thermal and Fluid Science, Vol. 5, No. 6, pp. 803-807.

Kays, W. M., and Crawford, M. E., 1993, Convective Heat and Mass Transfer, McGraw-Hill Book Company.

Kunugi, T., Yokomine, T., and Ichimiya, K., 1993, Numerical and Experimental Study on Heat Transfer of an Impinging Turbulent Plane Jet with Confined Wall, Heat Transfer in Turbulent Flows, Vol. 246, pp. 25-31.

Moffat, R. J., 1998, What's New in Convective Heat Transfer?, International Journal of Heat and Fluid Flow, Vol. 19, pp. 90-101.

Spalding, D. B., Agonafer, D., and Gan-Li, L., 1996, The LVEL Turbulence Model for Conjugate Heat Transfer at Low Reynolds Numbers, in: ASME International Mechanical Congress and Exposition, London.

Sparrow, E. M., and Wong, T. C., 1975, Impingement Transfer Coefficients Due to Initially Laminar Slot Jets, International Journal of Heat and Mass Transfer, Vol. 18, No. 5, pp. 597-605.

Wheeler, J., and Neti, S., 1999, Heat Transfer From a Semi-confined Impinging Laminar Jet, in: National Heat Transfer Conference.

Zuckerman, N., and Lior, N., 2006, Jet Impingement Heat Transfer: Physics, Correlations, and Numerical Modeling, Advances in Heat Transfer, Vol. 39, pp. 565-631. 